\title{
COMBINAÇÕES DE EMPRESAS PELO MÉTODO DE COMPRA DOS ATIVOS: ANÁLISE COMPARATIVA ENTRE AS NORMAS DO IASB E AS DO BRASIL
}

\author{
Christianne Calado Vieira de Melo Lopes \\ Professora do Departamento de Ciências Contábeis da UFPE \\ E-mail: christianne.lopes@ contabeis.ufpe.br
}

\section{RESUMO}

Este artigo apresenta os resultados de um estudo comparativo sobre uma das formas de combinações de empresas, definidas nas normas contábeis internacionais e brasileiras.

A pesquisa compara os principais pronunciamentos e normas contábeis - emitidos pelos órgãos normativos contábeis - internacionais e brasileiros - relativos às combinações de empresas pelo Método de Compra.

O estudo inclui, ainda, um caso prático para esta forma de combinação de empresa, baseado nas normas contábeis internacionais e brasileiras.

Finalmente, o estudo mostra que as normas contábeis brasileiras não contêm pronunciamentos explícitos sobre as combinações de empresas (método de compra); estas formas de associações de negócios são praticadas nas companhias brasileiras e são regulamentadas pelas leis brasileiras. O estudo também mostra que as companhias brasileiras fazem combinações de empresas pelo Método de Compra da mesma maneira como definidas pelas normas internacionais de contabilidade.

Palavras-chave: Combinações de Empresas, Método de Compra, Normas Internacionais e Brasileiras.

\section{ABSTRACT}

This article presents the results of a comparative study about one form of business combination, defined both by the international and Brazilian accounting standards.

The research compares the main pronouncements and accounting standards - issued by international and Brazilian accounting boards related to business combination in accordance with the purchase method.

The study also includes a practical case for this form of business combination, based on the international and Brazilian accounting standards.

Finally, the study shows that Brazilian accounting boards do not issue any explicit pronouncement about business combinations (purchase method) and that these forms of business association are practiced by Brazilian companies and are regulated by Brazilian laws. The study also demonstrates that Brazilian companies carry out business combinations through the purchase method in the same way as defined by international accounting standards.

Keywords: Business Combinations, Purchase Method, International and Brazilian Accounting Standards. 


\section{INTRODUÇÃO}

A globalização dos mercados constitui-se num fenômeno que mudou a estrutura econômica dos países, expandiu as fronteiras e permitiu que cada país pudesse extrapolar seus limites, em virtude da abertura dos mercados.

Essa tendência fez com que muitas empresas mudassem a tecnologia empregada, na busca de um melhor produto ou serviço, para evitar a redução de seu mercado consumidor.

Com as empresas mais globalizadas precisando da captação de recursos, principalmente nos mercados internacionais, torna-se de extrema importância a harmonização das normas contábeis entre os países envolvidos, visando minimizar as diversidades de cada país, uma vez que, critérios contábeis diferentes dificultam a comunicação entre as empresas. Conforme indica Hamilton:

É mais do que evidente a necessidade de um conjunto de normas aceito no mundo todo. Com o crescimento das empresas e a globalização de suas estruturas e atividades, muitas delas esgotaram a capacidade de seus mercados financeiros internos para proporcionar o capital que lhes permita crescer no ritmo mais adequado. Por isso, elas foram obrigadas a captar recursos em outros países. $^{1}$

A organização mundial responsável pela harmonização das práticas contábeis é o IASB International Accounting Standards Board ${ }^{2}$, cujo propósito é o de estabelecer um conjunto de normas contábeis (IAS - International Accounting Standards), que devem ser adotadas no mundo pelas empresas ao apresentarem suas demonstrações contábeis.

Nos dias de hoje, freqüentemente, mediante as várias formas de combinações, está ocorrendo a união das grandes e pequenas empresas trazendo muitos benefícios para as empresas combinadas. Telles ${ }^{3}$ comenta que:
A rápida consolidação das estruturas empresariais existentes, por meio das fusões e aquisições, é um indício de que o processo de integração econômica do mundo veio para ficar. A valorização imediata do capital das empresas recém-fundidas azeita e incentiva esses casamentos titânicos. Mas o que de fato os determina e sustenta são as enormes melhorias operacionais que geram:

- redução dos custos do capital;

- significativos ganhos reais em termos de eficiência e de inovação;

- enormes economias de escala no plano administrativo;

- alocação massiva de recursos em pesquisa e desenvolvimento;

- colossais investimentos na construção de marcas globais.

Portanto, estes são alguns dos fatores que as empresas estão buscando para unirem-se às outras.

O objetivo deste artigo é comparar as normas contábeis existentes no Brasil com os dispositivos internacionais, no que se refere a uma das formas de combinações de empresas - método de compra.

\section{COMBINAÇÕES DE EMPRESAS}

A definição apresentada por Beams ${ }^{4}$ para uma combinação de empresas é dada como sendo:

"União de entidades de negócios que se apresenta como alternativa para expansão ou desenvolvimento e que, freqüentemente, oferece vantagens para todas as entidades combinadas bem como para seus proprietários."

Por isso tais uniões geram, normalmente, algum tipo de benefício tanto para os negócios envolvidos como para os proprietários.

O IAS 22 é a norma internacional de contabilidade que trata das combinações de empresas.

De acordo com o IASB, uma combinação de

\footnotetext{
${ }^{1}$ HAMILTON, Stewart. A diversidade das normas contábeis. Gazeta Mercantil. Mastering Global Business - 1998.

${ }^{2}$ Comissão de Normas Internacionais de Contabilidade

${ }^{3}$ TELLES, Marcel. Caça ou caçador - quem não se internacionalizar, será internacionalizado. Revista Exame, nº 3, fev 2000, p. 138

${ }^{4}$ Apud El Hajj, Zaina Said. Business Combination e consolidação: uma abordagem comparativa entre as normas do US-GAAP, IASC e Brasil. São Paulo, 1999. p. 1. Dissertação (Mestrado em Controladoria e Contabilidade) - Faculdade de Economia, Administração e Contabilidade, Universidade de São Paulo. São Paulo.
} 
empresas é uma união de empresas distintas em uma única entidade econômica, como resultado de haver uma empresa se unido a outra ou haver obtido o controle sobre o seu ativo líquido e operações.

No âmbito internacional, considera-se que a combinação de empresas pode ser efetivada por meio de uma aquisição ou por uma união de interesses.

Já no Brasil, esse procedimento não é previsto desta forma, pois está atrelado à forma jurídica, sendo citado na Lei $n^{\circ}$ 6404/76 por meio das definições de fusão e incorporação.

\section{NORMAS INTERNACIONAIS DE CONTABILIDADE X NORMAS DE CONTABILIDADE BRASILEIRAS}

\section{a) Aquisição - IASB}

O IAS 22 define uma aquisição como sendo uma combinação de empresas em que a adquirente possui o controle sobre o ativo líquido e operações da adquirida, em troca da transferência de ativos, incorrência em um passivo ou emissão de ações de capital.

Num processo de combinação de empresas em que ocorre aquisição, uma das características principais é a figura da adquirente, cujo interesse resulta no controle da outra empresa, que é conhecida como adquirida.

No § 12, o IAS 22 descreve algumas indicações da existência da adquirente:

- a combinação de empresas torna a administração de uma empresa capaz de ter nas mãos a seleção da equipe administrativa da empresa resultante da combinação. Nestes casos, a empresa dominante é a adquirente;

- a combinação das empresas ocorre mediante uma troca de ações ordinárias, com direito a voto, por dinheiro. Nesses casos, a empresa que está fazendo o desembolso é a adquirente; ou

- o fair value ${ }^{5}$ de uma empresa é bem maior do que o da outra. A empresa maior é a adquirente. Verifica-se que essas indicações auxiliam nos fa- tores que devem ser observados na identificação da adquirente.

Quando uma empresa resolve adquirir outra empresa, a negociação do pagamento pode ser por meio da emissão de ações, dinheiro, equivalentes a dinheiro ou outros ativos ${ }^{6}$.

\section{b) Aquisição - BRASIL}

No Brasil não existem definições e caracterizações a respeito das formas de combinações, como descritas nas normas internacionais. No entanto, a legislação societária considera as combinações, apenas quanto à forma jurídica, embora na essência elas sejam praticadas.

Do ponto de vista formal, 'a linha geral das legislações tem sido a de considerar a fusão como um único instituto, que se desdobra em duas formas específicas: a fusão propriamente dita e a incorporação. A terminologia exprime com precisão os dois tipos, ou seja, pela constituição de nova sociedade, ou pela absorção de sociedade(s) por uma que remanesce. ${ }^{7}$ [grifos nossos]

No Brasil, a contabilização das combinações das empresas são mencionadas na Lei n ${ }^{\circ} 6404 / 76$ sob os aspectos de uma fusão ou incorporação, sendo por isso considerado apenas o aspecto formal.

Em substância, uma combinação de entidades resulta ou de um processo de aquisição em absoluto (compra de interesses) ou de um processo de união (comunhão) de interesses de propriedade. Esta distinção é a essência do evento econômico que determina primariamente a seleção e interpretação da sobrevivência da entidade relevante e que, portanto, pode ultrapassar os limites da consumação formal da transação. ${ }^{8}$ [grifo nosso]

Como pode-se observar, a substância (essência) econômica, na verdade, é um universo bem mais amplo no ambiente das combinações do que quando aplicada somente quanto à forma jurídica.

\section{c) Método da Compra - IASB}

Esse termo é conhecido em inglês como purchase method, e deve ser usado quando a combinação de

\footnotetext{
${ }^{5}$ Valor de mercado de uma empresa.

${ }^{6}$ IAS $22, \S 3$

${ }^{7}$ Bulgarelli apud Leão, Luciano de Castro Garcia. A unificação de patrimônios: essência versus forma em contabilidade. Revista Brasileira de Contabilidade. Ano XXX, n. ${ }^{\circ} 128$. Mar/abr 2001. p. 21

${ }^{8}$ Leão, op. cit., p. 22.
} 
empresas for representada por uma aquisição. A transação de troca é quem fundamenta a aquisição, pois os ativos e passivos são transferidos da adquirida para a adquirente.

A combinação das empresas pode envolver a aquisição do acervo líquido (inclusive o goodwill) da adquirida ou de suas ações, resultando num relacionamento matriz-subsidiária.

\section{d) Método da Compra - BRASIL}

Analisando o conceito do IAS 22 a respeito de aquisições, pode-se afirmar que, no Brasil, estas ocorrem, pois existe a figura do adquirente que obtém o controle sobre os ativos líquidos e operações de outra empresa, sendo portanto caracterizada a combinação de empresas. No entanto, os aspectos contábeis serão comparados, para que se possa destacar as diferenças existentes.

A aquisição no Brasil também pode ocorrer de duas formas: aquisição dos ativos líquidos ou pela aquisição de ações. O art. 223 da Lei n 6404/76 determina que a incorporação ou fusão podem ser operadas entre sociedades de tipos iguais ou diferentes. Poderá acontecer, por exemplo, uma aquisição em que seja gerada a união entre uma sociedade anônima e uma limitada.

\section{e) Aquisição dos Ativos Líquidos - IASB}

A aquisição do acervo líquido ou ativo líquido de uma empresa, inclusive o valor pago no que diz respeito ao goodwill é uma das formas de se adquirir uma empresa.

Embora os requisitos para essas combinações variem entre os países, acontece geralmente, entre duas companhias por meio da fusão ou incorporação.

\section{f) Aquisição dos Ativos Líquidos - Brasil}

Como a incorporação e fusão estão previstas na Lei $n^{\circ} 6404 / 76$, elas podem ser decorrentes da aquisição dos ativos líquidos da adquirida:

Art. 227. A incorporação é a operação pela qual uma ou mais sociedades são absorvidas por outra, que lhes sucede em todos os direitos e obrigações.
Art. 228. A fusão é a operação pela qual se unem duas ou mais sociedades para formar sociedade nova, que lhes sucederá em todos os direitos e obrigações. Analisando os conceitos acima, a lei não cita como sendo uma operação de aquisição, no entanto, a maioria das incorporações e fusões ocorre por intermédio da transação de compra caracterizando uma aquisição dos ativos líquidos.

\section{g) Critério de Avaliação - IASB}

De acordo com o § 21, do IAS 22, quando há uma aquisição numa combinação de empresas, deve-se contabilizá-la pelo custo ${ }^{9}$ mais quaisquer custos diretamente atribuíveis à aquisição.

Uma maneira muito simples de registrar o valor da aquisição é dada pelos autores Epstein \& Mirza $^{10}$ : "Aquisições devem ser registradas ao custo pago ou incorrido. Custo é o montante de caixa pago ou fair value de outra consideração dada para os acionistas da entidade adquirida."Os autores acima, destacam três situações que podem ocorrer numa aquisição:

1. Se o preço equivale ao fair value dos ativos líquidos, o processo de alocação será direto, com cada ativo sendo registrado ao fair value;

2. Se o fair value dos ativos líquidos identificáveis adquiridos é inferior ao preço pago, o excesso do custo deve ser alocado como goodwill (excesso do custo sobre o fair value dos ativos líquidos adquiridos);

3. Se o fair value dos ativos líquidos identificáveis adquiridos é superior ao preço pago, o excesso do valor deve ser alocado como goodwill negativo (excesso do fair value dos ativos líquidos sobre o custo).

Assim sendo, tem-se que ficar atento a uma dessas situações, a fim de que a aquisição seja contabilizada adequadamente.

Um outro ponto importante a ser destacado refere-se ao IAS 22, § 39, pois é fornecida uma orientação de como estabelecer o fair value, dos ativos e passivos adquiridos. Esse parágrafo é mostrado de forma resumida, no quadro a seguir, a fim de permitir uma melhor visualização e compreensão da forma como cada item patrimonial deve ser avaliado:

\footnotetext{
${ }^{9}$ Segundo o IASB, o custo é a importância em dinheiro ou equivalente pago, ou o fair value na data da troca de outra forma de pagamento dada pela adquirente em troca do controle sobre os ativos líquidos da outra empresa.

${ }^{10}$ EPSTEIN, Barry J.; MIRZA, Abbas Ali. IAS 97: interpretation and application of international accounting standards 1997. USA: Wiley, 1997.p. 338.
} 


\section{Avaliação dos ativos e passivos ao Fair Value}

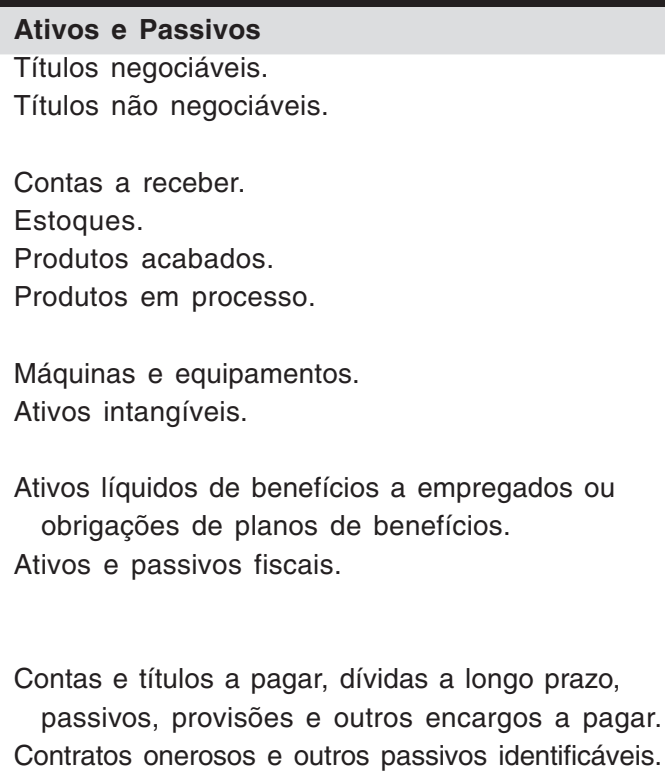

Ativos líquidos de benefícios a empregados ou obrigações de planos de benefícios.

Ativos e passivos fiscais.

Contas e títulos a pagar, dívidas a longo prazo, passivos, provisões e outros encargos a pagar. Contratos onerosos e outros passivos identificáveis.

\section{Fair Value}

Valor corrente de mercado.

Valores estimados baseados em coeficientes de lucros sobre o preço, rendimentos em dividendos, etc. Valor presente líquido.

Preço de venda - (custos de vendas + lucro razoável). Preço de venda dos produtos terminados - (custos para completar + custos de vendas + lucro razoável). Valor de mercado ou custo de reposição depreciado. Mercado ativo e caso este não exista, toma-se por base o montante que a empresa tenha pago o ativo.

Valor presente do benefício menos o fair value de quaisquer ativos do plano.

Importância do benefício fiscal decorrente de prejuízos fiscais ou impostos a pagar com respeito ao lucro líquido ou prejuízos.

Valor presente.

Valor presente.
Portanto, num processo de aquisição, os ativos e passivos adquiridos devem ser registrados ao fair value ou custo (preço pago na aquisição). Caso o valor pago na aquisição seja maior ou menor que o fair value, deve-se registrar o goodwill ou goodwill negativo incorridos na transação. No Brasil, o goodwill é denominado de ágio e o goodwill negativo de deságio.

\section{h) Critério de Avaliação - Brasil}

"Apesar de exigir a avaliação do patrimônio líquido, por meio de laudo pericial, a Lei $n^{\circ}$ 6404/76 não define os critérios de avaliação, somente vedando a incorporação dos bens ao patrimônio da empresa incorporadora, ou a resultante da fusão (...), por valor acima do que lhes tiver dado o subscritor. ${ }^{11}$ "

No caso de ocorrer uma incorporação, pela controladora, de companhia controlada, a Lei $n^{\circ} 6404 / 76$ permite a incorporação ${ }^{12}$ de controlada com base no valor do patrimônio líquido da adquirida e adquirente, avaliados ambos segundo os mesmos critérios e na mesma data, a preços de mercado. (art. 264).

\section{i) Exemplo Prático do Método da Compra com} a Aquisição dos Ativos Líquidos - Normas do IASB $\mathrm{X}$ Normas brasileiras

Vamos mostrar uma aplicação prática do método da compra quando ocorre a aquisição dos ativos líquidos, segundo as normas internacionais e brasileiras de contabilidade.

Com os exemplos apresentados pretende-se evidenciar os resultados patrimoniais neste tipo de combinação. Com esse propósito, foram consideradas as características necessárias para que ocorra uma aquisição. As empresas Delta e Gama resolveram combinar-se por meio do ato denominado de incorporação ${ }^{13}$. A empresa Delta é a adquirente e Gama a adquirida. Os Balanços Patrimoniais apresentados antes da aquisição são os seguintes:

\footnotetext{
${ }^{11}$ FIPECAFI \& ARTHUR ANDERSEN. Normas e práticas contábeis do Brasil. 2. ed. São Paulo: Atlas, 1994. p. 655.

${ }^{12}$ Aplicam-se a fusão de companhia controladora e controlada. (art. 264 e $\S 4 .^{\circ}$ ).

${ }^{13}$ Como visto anteriormente, a combinação pode ocasionar, também, uma fusão dos patrimônios.
} 


\begin{tabular}{l|r|r}
\hline BALANÇO PATRIMONIAL & Delta & Gama \\
\hline ATIVO CIRCULANTE & & \\
Disponível & 700 & 280 \\
Contas a receber & 180 & 110 \\
ATIVO PERMANENTE & & \\
Investimentos & 200 & - \\
Máquinas & 220 & 130 \\
Total Ativo & $\mathbf{1 . 3 0 0}$ & $\mathbf{5 2 0}$ \\
PASSIVO CIRCULANTE & & \\
Contas a pagar & 260 & 140 \\
Total Passivo & $\mathbf{2 6 0}$ & $\mathbf{1 4 0}$ \\
PATRIMÔNIO LíQUIDO & $\mathbf{1 . 0 4 0}$ & $\mathbf{3 8 0}$ \\
Total do Passivo + PL & $\mathbf{1 . 3 0 0}$ & $\mathbf{5 2 0}$ \\
\hline
\end{tabular}

A empresa Gama foi adquirida totalmente pela Delta pelo valor de $\$ 460$. Nesta aquisição foi tomado

como base para o registro contábil na adquirente, o fair value dos ativos e passivos adquiridos, cujos valores apresentaram as seguintes alterações:

- Contas a receber - \$120

- Máquinas - \$150

- Contas a Pagar - \$145

O Balanço Patrimonial da Gama, após a avaliação dos ativos e passivos (IASB e Brasil) é o seguinte:

\begin{tabular}{l|r}
\hline BALANÇO PATRIMONIAL & GAMA \\
\hline ATIVO CIRCULANTE & 280 \\
Disponível & 120 \\
Contas a receber & \\
ATIVO PERMANENTE & - \\
Investimentos & 150 \\
Máquinas & 550 \\
Total Ativo & \\
PASSIVO CIRCULANTE & 145 \\
Contas a pagar & 145 \\
Total Passivo & 405 \\
PATRIMÔNIO LíQUIDO & 550 \\
Total do Passivo + PL &
\end{tabular}

Como pode-se verificar, o ativo líquido da Gama estava sub-avaliado (\$380).

Pelas normas brasileiras, a adquirida apresentou novo valor contábil por meio da reavaliação (valor de mercado) das máquinas.

Após a aquisição, a empresa Delta apresentou a seguinte posição patrimonial de acordo com o IASB e as normas brasileiras:

\section{DELTA}

\begin{tabular}{l|r|r}
\hline BALANÇO PATRIMONIAL & IASB & BRASIL \\
\hline ATIVO CIRCULANTE & & \\
Disponível & 240 & 240 \\
Contas a receber & 180 & 180 \\
ATIVO PERMANENTE & & \\
Investimentos & 605 & 605 \\
Goodwill & 55 & 55 \\
Máquinas & 220 & 250 \\
Total Ativo & 1.300 & 1.330 \\
PASSIVO CIRCULANTE & & \\
Contas a pagar & 260 & 260 \\
Total Passivo & $\mathbf{2 6 0}$ & $\mathbf{2 6 0}$ \\
PATRIMÔNIO LíQUIDO & 1.040 & 1.070 \\
Total do Passivo + PL & $\mathbf{1 . 3 0 0}$ & $\mathbf{1 . 3 3 0}$ \\
\hline
\end{tabular}

Observa-se que os valores dos investimentos em Delta - IASB e Brasil - aumentaram para \$ 605 (\$200 + \$405), pois inicialmente adquire-se o controle (característica da aquisição) na Gama, para logo em seguida efetuar a união dos ativos líquidos.

No Brasil, o valor das máquinas apresenta um valor maior ( $\$ 250$ ), pois neste caso a adquirente reavalia seu ativo tangível permitindo, dessa forma, uma justa distribuição da participação acionária após a incorporação.

Como o fair value dos ativos líquidos identificáveis adquiridos (\$405) é inferior ao valor pago (\$460), o excesso (\$55) deve ser alocado como goodwill.

No Brasil, a Instrução CVM n ${ }^{\circ}$ 247/96 alterada em seu artigo 14 pela Instrução $\mathrm{CVM} \mathrm{n}^{\circ}$ 285/98, determina que o ágio ou o deságio computado na ocasião da aquisição ou subscrição do investimento deverá ser contabilizado indicando o fundamento econômico que o determinou. Neste caso, houve o reconhecimento dos ativos e passivos a valores de mercado, sendo que o goodwillsurgido na aquisição deve-se à expectativa de lucros futuros.

No caso da incorporação, os ativos e passivos da empresa Gama são transferidos para a empresa Delta e, neste caso, a primeira é dissolvida passando a existir apenas uma entidade que, agora, apresenta o seu patrimônio combinado. 
A situação patrimonial da empresa incorporadora (IASB X BRASIL) é apresentada a seguir:

\begin{tabular}{|c|c|c|c|c|c|c|c|c|}
\hline \multirow[b]{2}{*}{ BALANÇO PATRIMONIAL } & \multicolumn{2}{|c|}{ DELTA } & \multicolumn{2}{|c|}{ GAMA } & \multicolumn{2}{|c|}{ AJUSTES } & \multicolumn{2}{|c|}{ INCORPORADORA } \\
\hline & IASB & BRA & IASB & BRA & IASB & BRA & IASB & BRA \\
\hline \multicolumn{9}{|l|}{ ATIVO CIRCULANTE } \\
\hline Disponível & 240 & 240 & 280 & 280 & & & 520 & 520 \\
\hline Contas a receber & 180 & 180 & 120 & 120 & & & 300 & 300 \\
\hline \multicolumn{9}{|l|}{ ATIVO PERMANENTE } \\
\hline Investimentos & 605 & 605 & - & - & (1) (405) & (1) (405) & 200 & 200 \\
\hline Goodwill & 55 & 55 & - & - & & & 55 & \\
\hline Máquinas & 220 & 250 & 150 & 150 & & & 370 & 400 \\
\hline Ativo Diferido & & & & & & (2) (55) & & 55 \\
\hline Total Ativo & 1.300 & 1.330 & 550 & 550 & & & 1.445 & 1.475 \\
\hline \multicolumn{9}{|l|}{ PASSIVO CIRCULANTE } \\
\hline Contas a pagar & 260 & 260 & 145 & 145 & & & 405 & 405 \\
\hline Total Passivo & 260 & 260 & 145 & 145 & & & 405 & 405 \\
\hline PATRIMÔNIO LÍQUIDO & 1.040 & 1.070 & 405 & 405 & (1) (405) & (1) (405) & 1.040 & 1.070 \\
\hline Total do Passivo + PL & 1.300 & 1.330 & 550 & 550 & & & 1.445 & 1.475 \\
\hline
\end{tabular}

A conta de investimentos e o patrimônio líquido não apresentam em seus totais o somatório das duas empresas, haja vista que a Delta possui em seus registros contábeis investimentos efetuados na subsidiária Gama.

Por isso, quando esta for incorporada ao patrimônio daquela, deve-se fazer o lançamento $n^{\circ} 1$, eliminando os respectivos valores dos investimentos e sua parcela no patrimônio líquido. Vale ressaltar, que os lançamentos contábeis, para efeito de incorporação, também devem ser efetuados, tanto na Delta como na Gama.

O lançamento $n^{\circ} 2$ ocorre, apenas no Brasil, em função da Instrução CVM n ${ }^{\circ}$ 319/99, pois o montante do ágio na incorporadora, resultante da aquisição do controle, será contabilizado em conta específica do Ativo Diferido, quando o fundamento econômico tiver sido a expectativa de resultado futuro (art. $6^{\circ}$, III).

Para evidenciar as diferenças dos patrimônios líquidos pelas normas do IASB e as do Brasil, na incorporadora - Delta, será apresentada a conciliação do resultado:

Nesta conciliação, o patrimônio líquido da Delta incorporadora - de acordo com as normas brasileiras apresenta-se maior do que quando pelas do IASB, em virtude da reavaliação dos ativos tangíveis.

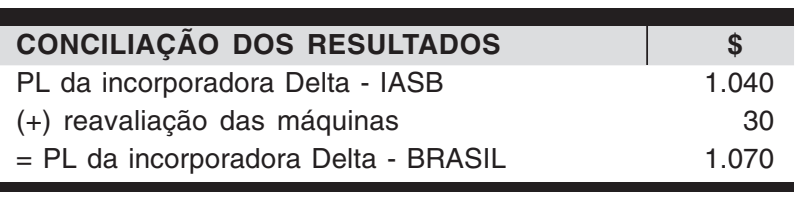

O patrimônio líquido da Delta, de acordo com o IASB, mostra-se subavaliado, pois na combinação de empresas só é aplicado o fair value dos ativos da adquirida ficando a adquirente com os seus ativos líquidos registrados ao valor histórico.

A partir dos exemplos apresentados, conclui-se que no Brasil se pratica essa forma de combinação; e os principais fatores que os diferenciam das normas internacionais são:

a) o tratamento contábil a ser dado ao ágio na incorporadora, resultante da aquisição do controle da adquirida. Segundo o IASB, apresenta-se como goodwill, e no Brasil é transferido para o Ativo Diferido.

b) no Brasil, na aquisição dos ativos líquidos é utilizado o valor de mercados dos ativos e passivos tanto da adquirida como da adquirente, apresentando uma avaliação mais consistente para os patrimônios envolvidos na combinação. O IASB somente utiliza o fair value dos ativos e passivos da adquirida. 


\section{ANÁLISE COMPARATIVA DO MÉTODO DE COMPRA - NORMAS DO IASB X NORMAS BRASILEIRAS}

O quadro a seguir, mostra as fontes normativas a respeito das combinações de empresas pelo método de compra. No caso do Brasil, como não estão previstas as formas de combinações, buscou-se as bases normativas das aquisições e uniões de interesses a partir da Lei n ${ }^{\circ}$ 6404/76 e da Instrução CVM n 247/96.

\begin{tabular}{l|c|c}
\hline & IASB & BRASIL \\
Formas de Combinações & IAS 22 - Combinações & Não está previsto em \\
nenhuma norma & Não está previsto em \\
Método da Aquisição & de Empresas & nenhuma norma \\
Aquisição dos Ativos Líquidos & adquirente (IAS 22, §11) & fusão ou incorporação \\
& fusão ou incorporação & Lei $\mathrm{n}^{\circ}$ 6404/76 - (art. 227 e 228)
\end{tabular}

Observa-se que as formas de combinações de empresas segundo as normas internacionais de contabilidade são praticadas no Brasil, faltando portanto nas normas de contabilidade brasileiras o seguinte aspecto:

$\rightarrow \mathrm{O}$ estabelecimento da forma de combinação pela aquisição prevista pelo IASB, com a aplicação do critério de avaliação na aquisição, para as empresas envolvidas na combinação com base no valor de mercado dos ativos e passivos.

Assim, os critérios de avaliação relativos à forma de combinações de empresas de acordo com o IASB seriam aplicados em parte no Brasil.

\section{CONSIDERAÇÕES FINAIS}

Com o mercado globalizado, as empresas estão buscando cada vez mais investir em outros países e muitas vezes buscam a combinação com outras empresas através dos processos de aquisições. Como cada país adota suas práticas contábeis, o IASB busca uma maior harmonização e assim tenta minimizar as diversidades entre os países.
Verifica-se que não há no Brasil nenhum pronunciamento que trate de combinações de empresas, como se tem nas normas internacionais.

Como as combinações de empresas podem resultar em uma fusão ou incorporação, as bases normativas a respeito destas combinações encontram-se na Lei $n^{\circ}$ 6404/76.

A diferença básica entre as normas do IASB e as do Brasil diz respeito ao tratamento contábil dado aos elementos patrimoniais, uma vez que o IASB considera apenas o fair value da empresa adquirida, enquanto que no Brasil é reconhecido o valor de mercado dos ativos e passivos tanto da adquirida como da adquirente.

Diante do exposto, sugere-se que os órgãos normatizadores brasileiros incluam as formas de combinações de empresas em nossa legislação.

Incorporando estes avanços que fazem parte das práticas internacionais, o Brasil estará contribuindo para a harmonização contábil buscada pelo IASB.

\section{REFERÊNCIAS BIBLIOGRÁFICAS}

A CONSOLIDAÇÃO proporcional - regras da CVM quanto aos aspectos contábeis dos investimentos nos Joint Ventures. Boletim Temática Contábil e Balanços - IOB São Paulo, Bol. № 49/97.

AS DEMONSTRAÇÕES financeiras na era da globalização. Revista Trevisan, ano VII, $\mathrm{n}^{\circ}$ 89, jul. 1995, p. 16-17.

BRASIL. Lei $n^{\circ} 6.404$, de 15 de junho de 1976. Dispõe sobre as sociedades por ações.

COMISSÃO DE VALORES MOBILIÁRIOS, CVM. Instrução CVM $n^{\circ} 15 / 80$.
Instrução n 247, de 27 de março de 1996.

Instrução n² 285, de 31 de julho de 1998.

Instrução $n^{\circ}$ 319, de 03 de dezembro de 1999.

Ofício-Circular CVM/SNC/SEP $/ n^{\circ} 04$, de 27 de dezembro de 1996. Dispõe sobre Equivalência Patrimonial e Consolidação.

Normas brasileiras de contabilidade - NBC T8 - Das demonstrações contábeis consolidadas. 
EL HAJJ, Zaina Said. Business Combination e consolidação: uma abordagem comparativa entre as normas do US-GAAP, IASC e Brasil. São Paulo, 1999. Dissertação (Mestrado em contabilidade) - Faculdade de Economia, Administração e Contabilidade, Universidade de São Paulo.

EPSTEIN, Barry J.; MIRZA, Abbas Ali. IAS 97: interpretation and application of internacional accounting standards 1997. USA: Wiley, 1997.

FIPECAFI - Fundação Instituto de Pesquisas Contábeis, Atuariais e Financeiras. Manual de contabilidade das sociedades por ações: aplicável também as demais sociedades. $5^{a}$ ed. São Paulo: Atlas, 2000.

FIPECAFI \& ARTHUR ANDERSEN. Normas e práticas contábeis do Brasil. $2^{a}$ ed. São Paulo: Atlas, 1994.

GODOY, Carlos Roberto de. Comparação teórica e prática entre os métodos de contabilidade para combinações de empresas. São Paulo, 2000. Dissertação (Mestrado em Contabilidade) - Faculdade de Economia, Administração e Contabilidade da Universidade de São Paulo.

HAMILTON, Stewart. A diversidade das normas contábeis. Gazeta Mercantil. Mastering Global Business - 1998.

HENDRIKSEN, Eldon S; BREDA, Michael F. Van; tradução de Antonio Zoratto Sanvicente. Teoria da contabilidade. São Paulo: Atlas, 1999.
IASB - International Accounting Standards Committee: IAS 22 - Business Combination - Combinação de Empresas. Emitido em 1983 e revisado em 1998.

International Accounting Standards Committee. Understanding IAS: analysis and interpretation. United Kingdom: Coppers \& Lybrand, 1996.

Normas internacionais de contabilidade. São PauIo: IBRACON, 1998.

NOVAS regras da CVM quanto aos aspectos contábeis dos investimentos nas Joint Ventures. Boletim Temática Contábil e Balanços - IOB. $1^{\text {a }}$ parte. São Paulo, Bol. n $30 / 96$.

KREISER, Larry; SPERO, Abba. Pooling: going...going...gone? The Ohio CPA Journal. February, 1997.

LEÃO, Luciano de Castro Garcia. A unificação de patrimônios: essência versus forma em contabilidade. Revista Brasileira de Contabilidade. Ano XXX, n 128. Mar/abr 2001. p. 19-33.

SIEGEL, Joel G.; SHIM, Jae K. Dictionary of accounting terms. 2 nd. Ed. USA: Barron's, 1995.

TELLES, Marcel. Caça ou caçador - quem não se internacionalizar, será internacionalizado. Exame, n 3, 9 fev 2000. 